\title{
ESPORTE: UM CONTEÚDO EXCLUDENTE OU INCLUSIVO NA EDUCAÇÃO FÍSICA ESCOLAR?
}

Camila Lopes Carvalho, Universidade Estadual de Campinas - UNICAMP, Campinas, São Paulo - Brasil

Paulo Ferreira de Araújo, Universidade Estadual de Campinas - UNICAMP, Campinas, São Paulo - Brasil

\section{RESUMO}

A inclusão das pessoas com deficiência na rede regular de ensino é um direito legal, e as disciplinas, inclusive a educação física, caminham buscando sua adequação segundo as diferentes realidades. O esporte é um dos conteúdos da educação física escolar e, após um passado no qual teve atuação enfatizando a exclusão, atualmente está imerso numa nova realidade de busca por uma forma de atuação pedagógica inclusiva. Consciente do relevante prestígio social deste conteúdo e das possibilidades de alcance de seus ideais frente a esse prestígio, o presente trabalho objetiva refletir sobre a participação das pessoas com deficiência no conteúdo do esporte e as possibilidades de contribuição deste à inclusão na educação física escolar, por meio de revisão bibliográfica a respeito do tema educação física escolar, esporte e inclusão. Como conclusão, pode ser observado que, apesar de em grande período histórico esse conteúdo ser explorado como forma de segregação dos menos habilidosos, e ainda ser entendido socialmente como busca pela perfeição técnica, no âmbito educacional o esporte tem potencial para estimular a cooperação e valorização das diferentes potencialidades do aluno possibilitando, por meio de seu prestígio e influência, a transformação de ideais e a contribuição para a construção da inclusão.

Palavras-Chave: Inclusão; Educação física; Esporte.

\section{SPORT: AN EXCLUSIVE OR INCLUSIVE CONTENT IN SCHOOL PHYSICAL EDUCATION?}

\begin{abstract}
The inclusion of people with disabilities in regular education is a legal right, and disciplines, including physical education, go looking for their suitability according to different realities. The sport is one of the contents of school physical education and after a past in which action had emphasizing exclusion, is also currently immersed in a new reality search for a form of inclusive educational practice. Aware of relevant social prestige of this content and the possibilities of reaching their ideals against that reputation, this work aims to reflect on the participation of people with disabilities in sport content and potential contribution of the inclusion in physical education, for reviewed the literature on the subject physical education, inclusion and sport. In conclusion, it can be seen that although a large historical period that content be explored as a means of segregation of less skilled and still be understood as socially quest for technical perfection, in the educational
\end{abstract}


context the sport has the potential to stimulate cooperation and appreciation the different capabilities of each student, enabling through their prestige and influence the transformation of ideals and the contribution to the construction of inclusion.

Key-Words: Inclusion; Physical education; Sport.

\title{
DEPORTE: UN CONTENIDO EXCLUSIVO O INCLUSIVO EN LA EDUCACIÓN FÍSICA DE LA ESCUELA?
}

\begin{abstract}
RESUMEN
La inclusión de las personas con discapacidad en la educación regular es un derecho legal, y las disciplinas, incluyendo la educación física, ir en busca de su idoneidad de acuerdo a las diferentes realidades. Deporte es uno de los contenidos de la educación física y después de un pasado en el que la acción había enfatizando la exclusión, se encuentra inmersa en una nueva búsqueda de la realidad de una forma de la práctica educativa inclusiva. Así, este trabajo tiene como objetivo reflexionar sobre la participación de las personas con discapacidad en los contenidos deportivos, por revisado la literatura sobre el tema de la educación física, deporte y la inclusión. En conclusión, se puede observar que apesar de un período histórico de gran tamaño que el contenido se explorará como un medio para la segregación de los menos cualificados y todavía ser entendida como la búsqueda de la perfección técnica social, en el contexto educativo tiene el potencial de estimular la cooperación y la apreciación las diferentes capacidades de cada estudiante, lo que permite a través de su prestigio e influencia de la transformación de los ideales y la contribución a la construcción de la inclusión.
\end{abstract}

Palabras-Clave: Inclusión; Educación física; Sport. 


\section{INTRODUÇÃO}

As pessoas com deficiência passaram por períodos de repleta rejeição e abandono, sendo até mesmo condenadas à morte na antiguidade. Até serem vistas como seres humanos e alcançarem aceitação e respeito, árduas batalhas foram travadas para conquistarem espaço e direitos na sociedade.

Em relação à educação física, sua prática já sistematizada ocorreu no século XIX na Europa, sendo difundida pelo mundo por meio de métodos de ginásticas baseados em aspectos puramente físicos, contribuindo para um início da educação física escolar de forma excludente, ao dificultar a participação de pessoas que não tivessem o padrão de aptidão física estipulada como ideal, como no caso das pessoas com deficiência. ${ }^{1}$

Os acontecimentos dentro de uma sociedade não ocorrem de forma isolada, mas entrelaçados por questões políticas e circundados por um contexto histórico, interligando a busca pela aceitação social das pessoas com deficiência a esse contexto das aulas de educação física escolar.

Os conteúdos dessa disciplina escolar foram, por conseguinte, seguindo esse caminhar, transpassando uma função de exaltação dos mais habilidosos para a valorização e difusão da aceitação das diferenças e respeito pelas características e potencialidades individuais.

Nesse contexto, o esporte possui posição de destaque, considerando sua valorização cultural exacerbada no país e presença indispensável nas aulas de educação física.

Por conseguinte, este trabalho objetiva refletir sobre a participação das pessoas com deficiência no conteúdo do esporte e as possibilidades de contribuição à inclusão na educação física escolar por meio desse conteúdo. Dessa forma, é contextualizado o caminho percorrido pela educação física escolar e a busca das pessoas com deficiência para alcançarem aceitação e respeito social para, por conseguinte, compreender o esporte neste cenário. Para isso, esse trabalho foi desenvolvido por meio de uma revisão bibliográfica, com fontes impressas da base de dados da Faculdade de Educação Física da Universidade Estadual de Campinas, sobre o tema de educação física escolar, inclusão, pessoas com deficiência e esporte. A pesquisa bibliográfica pode ser compreendida como 
uma forma de trabalho na qual o qual o pesquisador reflete sobre um determinado tema por meio da retomada de publicações já existentes sobre o assunto, possibilitando a ampliação de conhecimento e também fundamentação para posteriores ideias. ${ }^{2}$ Assim, para essa pesquisa, foram utilizados os termos “educação física” e “inclusão” combinados no endereço eletrônico de busca da biblioteca dessa Faculdade de Educação Física. Como critério de inclusão foram utilizados os livros no idioma português cuja temática era consonante com o objetivo deste estudo. Já os trabalhos de conclusão de curso, teses, dissertações não foram analisados, assim como os livros cuja temática não discutia especificamente a questão aqui retratada ou em outra língua que não o português. Dessa forma, foram encontradas 18 obras, das quais 8 se enquadraram ao critério de inclusão.

Espera-se, portanto, que esse trabalho contribua com reflexões acerca da prática e forma de exploração desse conteúdo nas aulas de educação física escolar, de forma a contribuir com a qualidade da atuação dos professores e também com a construção da educação física de forma inclusiva.

\section{A PESSOA COM DEFICIÊNCIA, O ESPORTE E A INCLUSÃO EDUCACIONAL}

Assim como a escola influencia, ela também é influenciada pela sociedade na qual está inserida. Sendo indissociável uma da outra, um estudo dessa relação torna-se relevante para a compreensão da inclusão e de suas possibilidades na educação física escolar. Para isso, é necessária a compreensão do caminho percorrido pela pessoa com deficiência e pela educação, e seu conteúdo esporte, até encontrarem-se no atual cenário em busca da educação inclusiva.

Essa retomada permite contextualizações não apenas do passado, mas também compreensão dos questionamentos presentes e possibilidades de atuação para práticas futuras.

\section{A PESSOA COM DEFICIÊNCIA}

Desde a antiguidade há relatos da presença de pessoas com algum tipo de deficiência. Sabendo que nesse período o ser humano dependia de suas próprias características para 
caçar, fugir e sobreviver, as pessoas com essa condição eram vistas como empecilho, sendo comumente abandonadas. ${ }^{3}$

Com o início da organização social, o conhecimento baseado no misticismo prevaleceu, e as pessoas com deficiência eram, em sua maioria, abandonadas ou condenadas à morte, já que a deficiência passou a ser entendida como um castigo por pecados de vidas anteriores ou devido à presença de algum mau espírito. Já na Idade Média, com a dominação cristã, houve a propagação de que pessoas com essa condição também possuíam alma, a caridade para com elas poderia ser uma forma das demais de alcançarem a vida eterna. A fase de extermínio dessa população passou, então, a ser substituída pelo assistencialismo, no qual locais, como as Santas Casas de Misericórdia, recebiam essa população e garantiam sua sobrevivência, contudo de forma isolada do restante social. ${ }^{3}$

Com difusão da concepção Humanista e a valorização de todos os seres humanos, discussões a respeito da possibilidade de educação para pessoas com deficiência distenderam-se. Neste contexto, o primeiro educador oficialmente reconhecido para pessoas com deficiência foi Pedro Ponce que, em 1500 aproximadamente, passou a ensinar os filhos com surdez dos nobres. Ademais, Charles Michel L’Epépe, no século XIV, iniciou o trabalho com método de sinais para pessoas surdas; Louis Braille criou o Método de Leitura Braille para pessoas cegas; e Jean Marc Itard propôs uma metodologia educacional para o menino Victor, um menino selvagem com dificuldades intelectuais, proporcionando iniciais possibilidades de educação para pessoas com essa condição específica de deficiência. ${ }^{4}$

Surgiu, em seguida, uma fase de institucionalização com a criação de instituições especiais com caráter também educacional para atender essas pessoas, com influência da psicologia e pedagogia nesse campo até então dominado pelos médicos, de forma paralela as escolas regulares. O relato da primeira instituição especializada oficial é de 1817, quando Thomas Gallaudet criou o Asilo Norte-Americano para Educação e Instrução dos Surdos e Mudos. ${ }^{5}$

No Brasil, a primeira instituição especial foi o Imperial Instituto dos Meninos Cegos, criada por Dom Pedro II, no século XIX. Em seguida, foi implantado o Instituto dos Mudos e Surdos, o qual foi transformado em Instituto Nacional de Educação para Surdos 
posteriormente. Sem continuidade política na questão, coube às iniciativas populares a continuação na criação de organizações especiais. ${ }^{6}$

Já no século XX, novas pesquisas metodológicas de educação e a proliferação de vários movimentos sociais em defesa dos direitos das pessoas com deficiência, liderados principalmente por familiares dessas pessoas, influenciaram a forma como as pessoas com deficiência eram tratadas, questionando a segregação e defendendo o direito de todas as pessoas aos mesmos direitos sociais, inclusive referentes à educação.

Neste contexto, na década de 50 a sociedade brasileira transitou de uma fase de normalização - a qual visava proporcionar às pessoas com deficiência uma vida próxima dos padrões considerados normais pela sociedade, porém dentro das instituições segregadas - para uma de integração - na qual as pessoas com deficiência eram preparadas para participarem dos ambientes sociais já estabelecidos. Com isso, as pessoas com deficiência passaram a frequentar as escolas regulares por meio da criação de classes especiais separadas dos demais mas dentro destas escolas. ${ }^{7}$

Com esse início, o Ministério de Educação e Cultura (MEC), em 1972, com o "GrupoTarefa de Educação Especial”, criou por meio do Decreto $n^{\circ} 72.425$, de 03 de julho de 1973, pelo artigo $3^{\circ}$, inciso VI, o “Centro Nacional de Educação Especial” (CENESP), que se constituiu como uma primeira política educacional específica para a educação de pessoas com deficiência. Este, em 1986, foi substituído pela Secretaria de Educação Especial e, na década de 90, pelo Estatuto da Criança e do Adolescente, mas manteve o ideal de que toda criança e adolescente com alguma condição de deficiência tem o direito de receber atendimento especializado, com dever do governo em ofertá-lo no sistema regular sempre que possível. ${ }^{8}$

Com atuação relevante no estímulo das ações posteriores, o ano de 1981 foi definido como o Ano Internacional das Pessoas Portadoras de Deficiência, pela Organização das Nações Unidas, induzindo os países a realizarem ações em todas as áreas relacionadas às pessoas com deficiência. 
Nas décadas de 80 e 90, a inclusão social substituiu o ideal da integração, o qual não mais se sustentava em face das transformações de conhecimento e consciência referentes aos direitos e capacidades individuais. Consequentemente, no cenário educacional, essa temática foi defendida pela Declaração Mundial sobre Educação para Todos e, em 1994, a Declaração de Salamanca, na Conferência Mundial sobre Necessidades Educacionais Especiais, realizada na Espanha, definiu o conceito de inclusão escolar, o qual impõe como responsabilidade da escola, com toda sua estrutura, recursos e funcionários, se adaptar para receber e proporcionar a mesma qualidade de ensino para todos, independente de suas dificuldades. ${ }^{5}$

Essas propostas internacionais foram ratificadas pelo governo brasileiro, o qual redefinindo a educação especial como uma educação para pessoas com deficiência a ser oferecida preferencialmente na rede regular de ensino.

No ano de 1999, pelo Decreto $n^{\circ}$ 3.076, foi criado o Conselho Nacional dos Direitos da Pessoa Portadora de Deficiência (CONADE), com finalidade de acompanhar as políticas nacionais referentes à inclusão social das pessoas com deficiência. Em 2001, foi elaborado o Plano Nacional de Educação, primeiro plano brasileiro destinado a acompanhar a sanar as principais dificuldades educacionais do país, já conjecturando com a construção de uma educação inclusiva.

Apesar de estabelecida nos planos legais e acadêmicos, a inclusão enfrenta uma árdua batalha para ser concretizada nas realidades escolares. Falta de adaptação de currículos e materiais; e falta de preparo profissional e de apoio especializado ainda são um entrave. Porém, se implantada como determinado pelos documentos acadêmicos e políticos, a inclusão poderá trazer inúmeros benefícios não apenas para a instituição escolar e seus alunos, mas para toda a sociedade, como o melhor preparo das pessoas para viverem em comunidade, a melhor capacitação dos professores, o desenvolvimento de valores como compreensão, respeito, solidariedade, respeito às diferenças, e auxilio na mudança e eliminação de atitudes de discriminação e preconceito. 5, 9

A inclusão envolve questões históricas e sociais, assim como a escola, e uma mudança envolvendo esse cenário não será rápida nem fácil de ser implantada, porém com 
planejamento e atuação pedagógica adequada, toda mudança no cenário educacional poderá ser feita, corroborando com os ideais de Freire. ${ }^{10}$

\section{CONTEXTUALIZAÇÃO DA EDUCAÇÃO FÍSICA NO BRASIL}

Os conteúdos os quais hoje compõe a educação física possuem uma história intimamente atrelada à origem da humanidade. De início, com um homem nômade e dependente de seus próprios esforços físicos para a sobrevivência, atividades como a corrida e o nado já eram presentes no cotidiano. Posteriormente, com o estabelecimento de sociedades como com as Cidades-Estados de Roma e Grécia, essas atividades físicas também passaram a ser organizadas com regras e normas. Já no século XVIII, essas práticas foram sistematizadas com a formação de métodos ginásticos, na Alemanha, Suécia e França, adquirindo, pela primeira vez, o nome de educação física. ${ }^{11}$

Com grande desenvolvimento econômico, a Europa buscava, nesta época, trabalhadores qualificados fisicamente, uma vez que o trabalho era predominantemente manual, organizando esses métodos com ênfase em aspectos da aptidão física. Com relevante importância econômica da Europa nesse momento, os métodos ginásticos influenciaram todo o mundo, também se difundindo no Brasil por meio da criação de escolas de ginástica que, visando a formação de cidadãos saudáveis e fortes para o exército, tratavam os alunos de forma homogênea, exigindo os mesmos exercícios e padrões de resultados para todos. ${ }^{1}$

Sabendo que a educação física passou a fazer parte do ambiente escolar inicialmente na Europa, no século XIX, no Brasil o inicio oficial dessa disciplina deu-se neste mesmo século quando, em 1854 a modalidade de ginástica passou a fazer parte do ensino primário e a dança no ensino secundário, com a Reforma Couto Ferraz. ${ }^{12}$ Contudo, isso não impedia que tais práticas já não ocorressem nesse ambiente antes desse período, contudo ainda sem oficialização enquanto currículo escolar.

Baseada em aspectos higiênicos - com a busca de corpos saudáveis - e eugênicos objetivando a formação de uma raça padronizada utopicamente com um biológico prédeterminado -, médicos e militares enfatizavam o desenvolvimento de aptidões físicas visando a formação de bons soldados para a defesa da pátria e cidadãos saudáveis para o mercado de trabalho. Posteriormente, uma esportivização abrangeu a área, trazendo os 
ideais sociais de concorrência e rendimento para as atividades físicas e, num momento político de tentativa de centralização do poder nacional, visou a alienação dos cidadãos. ${ }^{13}$

Nessa padronização de uma forma física perfeita, as pessoas com deficiência não tinham possibilidade de vivência de tais práticas. Como exemplo é possível ser citado o Decreto $\mathrm{n}^{\circ}$ 21.241 da Portaria ${ }^{\circ} 13$ e 16, de fevereiro de 1938, que proibia que alunos que tivessem alguma patologia ou características que os impedisse de participar das aulas de educação física fossem matriculados em instituições de ensino secundário. ${ }^{13}$ Não mais proibindo, mas ainda excluindo, em 1971, a Lei ${ }^{\circ}$ 5.692/71 passou a dispensar os alunos com alguma deficiência das aulas de educação física, sem considerar as especificidades e capacidades nas diversas dimensões que cada um poderia desenvolver através dos estímulos proporcionados pela sua prática. ${ }^{14}$

Num processo de transformações desses ideais, a visão tanto da educação física quanto da sociedade foi sendo reconstruída de forma a considerar as pessoas de forma mais humana e respeitosa, iniciando a aceitação das diferenças e já considerando a participação de pessoas com deficiência. Assim, em 1952 surgiu o termo Educação Física Adaptada, designada como uma educação física que possui alunos com deficiência entre os demais da turma e adapta suas atividades de acordo com a necessidade de cada um. ${ }^{15-16}$

Em 20 de dezembro de 1961, foi instituída no Brasil a primeira Lei de Diretrizes e Bases da Educação, Lei n. 4024, que tornou obrigatória a Educação Física nos cursos primário e médio, consolidando a educação física enquanto disciplina escolar. Esta mesma lei define que a educação das pessoas com deficiência deveria ocorrer no sistema regular de educação quando fosse possível, com o objetivo de integrá-los socialmente. ${ }^{17}$ Essa lei reflete as mudanças sociais que se iniciaram com a propagação humanista, e o início da propagação da concepção de integração. Apesar de não garantir medidas que auxiliassem na presença das pessoas com deficiência na escola, essa lei passou a considerar essa possibilidade explicitamente, pela primeira vez na história do Brasil, aproximando a pessoa com deficiência da prática da educação física escolar.

Se até os anos de 1970 a educação física foi utilizada de acordo com os interesses políticosociais, como pode ser visto nos parágrafos anteriores, somente a partir desta década que o 
objetivo da área e o processo de ensino-aprendizagem passaram a ser questionados, iniciando a consideração às outras dimensões além da física, à finalidade e à forma de atuação mais adequada para a área. Surgiram, por conseguinte, abordagens ou teorias, que propuseram formas de atuação para a educação física considerando as diferentes dimensões como a afetiva, cognitiva, sociocultural e psicológico, além da motora. Dentre estas, pode-se exemplificar citando a da psicomotricidade, a desenvolvimentista, a construtivista-interacionista, as críticas superadora e emancipatórica.

Concomitantemente, em 21 de novembro de 1978 foi aprovada a Carta Internacional de Educação Física e Desportos, pela Conferencia da Organização das Nações Unidas (UNESCO), estabelecendo a educação física e o desporto como um direito de todos tanto no sistema educativo quanto em outros setores sociais, inclusive das pessoas com deficiência.

No ano de 1987, o Conselho Federal de Educação estabeleceu a Resolução n03, Parecer n 215, no qual propôs a inserção da disciplina de Educação Física Adaptada nos cursos de graduação de educação física do país. ${ }^{18}$ Sendo os cursos de graduação destinados à formação de professores de educação física, este tem grande influência na capacitação e preparo desses profissionais para essa nova realidade. Dessa forma, a inserção de uma disciplina específica para o estudo das atividades físicas para pessoas com deficiência tem aspectos positivos tanto na consideração dessas pessoas em âmbito acadêmico quanto no preparo desses professores para atuarem com essas pessoas fora da universidade. Passouse, portanto, não apenas a considerar a participação das pessoas com deficiência na educação física, mas também iniciou uma preocupação em capacitar os profissionais para desempenharem uma atuação adequada, considerando o direito dessas em receberem uma orientação com a mesma qualidade que os demais.

Já no ano de 1988, segundo Gorgatti e Costa, ${ }^{19}$ foi criado em Minas Gerais, o primeiro curso de especialização em Educação Física Adaptada, proporcionando seriedade e desenvolvimento dos estudos acadêmicos na área, contribuindo de forma efetiva com a formação de mais professores capacitados para tal atuação. 
Em 1999, foi criada uma Comissão de Especialistas (COESP), vinculada à Secretaria de Ensino Superior do Ministério da Educação (SESu/MEC) com o objetivo de definir as diretrizes curriculares, ou seja, uma base de conteúdos a serem trabalhados por cada curso. Sobre a educação física, ficou definido como objetivo o estudo do movimento humano, devendo esse curso superior proporcionar uma formação generalista, humanista e crítica. ${ }^{20}$ Considerando que a finalidade da escola é, não só transmitir, mas também praticar e reinventar dados da cultura, Vago ${ }^{21}$ justifica a necessária presença da educação física como componente curricular escolar. Por conseguinte, a autora esclarece que os conteúdos da educação física, como a ginástica, jogo, esporte, dança e luta, também fazem parte da cultura humana, sendo importantes em nível de serem considerados como um patrimônio cultural ao qual os alunos têm direito ao acesso tendo, a presença da disciplina de educação física na escola, um desígnio relevante e justificado. Pode-se observar a grande mudança e evolução desta área em tão pequeno espaço de tempo.

Por conseguinte, a educação física deixou de ser privilégio de poucos e tem se transformado de excludente para inclusiva, ao mudar e definir sua função e forma de atuação, buscando uma atuação numa perspectiva que proporcione que todos os alunos vivenciem os movimentos e os conteúdos da cultura corporal, sabendo que os professores não devem considerar apenas o corpo biológico do aluno, mas as histórias, culturas e contextos sociais imbuídos nestes. No âmbito escolar, a educação física, portanto, não deve atentar-se em execuções de técnica de forma eficiente, mas sim proporcionar conhecimentos e vivências a respeito dos diversos conteúdos relacionados ao movimento corporal valorizados culturalmente por um grupo, proporcionando ao aluno não apenas sua prática, mas também o desenvolvimento de sua visão crítica e autônoma de forma a permitir uma atuação na própria transformação dessa prática, tornando-a cada vez mais acessível a todos.

\section{ESPORTE NA EDUCAÇÃO FÍSICA: POSSIBILIDADE DA INCLUSÃO EDUCACIONAL}

A participação da pessoa com deficiência no sistema educacional é, além de uma obrigação legal, um direito humano. A educação física escolar, que inicialmente teve função excludente numa história marcada pela padronização de corpos, hoje luta pela 
consolidação de uma atuação inclusiva, com atividades adaptadas de acordo com as necessidades de cada aluno.

Neste contexto, um dos conteúdos da educação física é o esporte. Este teve sua origem através dos jogos populares, que foram adquirindo regras e buscando rendimento e recordes, transformando-se nos esportes modernos no século XIX. Essa transição ocorreu nas escolas públicas burguesas da Inglaterra, país este que, com intensa industrialização e urbanização social, foi construtor e difusor de uma estrutura capitalista, difundindo consequentemente o esporte moderno aos demais países conjuntamente ao modelo econômico. Observa-se, portanto, que inicialmente o esporte foi restrito as altas classes sociais, porém em seguida se popularizou e massificou, transformando-se num grande espetáculo de rendimento, em cultura popular e também num expressivo mercado financeiro. ${ }^{22}$

Bracht ${ }^{23}$ ressalta que alguns autores consideram os jogos antigos, como os gregos, já como um esporte, contudo, as características definidoras do esporte atual como ênfase na competição, o rendimento físico e técnico, busca pelo recorde, a racionalização e a fundamentação científica do treino, foram impostas apenas a partir desse período.

Após esse inicio, o esporte adquiriu uma importância cultural incomensurável, sendo impossível negligenciar sua presença e relevância sociocultural.

Já a participação das pessoas com deficiência nesse conteúdo teve início oficial apenas no ano de 1944, quando criado o esporte adaptado, o qual foi elaborado para essa população específica. $^{6}$

Neste ano, Dr. Ludwing Guttmann, um médico judeu refugiado da Alemanha nazista fundou, no Hospital de Stoke Mandeville, na Inglaterra, um centro de reabilitação, utilizando o esporte como forma de tratamento dos soldados que voltavam dos combates lesionados - principalmente com lesão medular - por acreditar que esse conteúdo trabalharia não apenas com a dimensão física, mas também a psicossocial. Já no ano de 1948, esse mesmo médico organizou os Jogos de Mandeville, destinados a competições esportivas entre esses soldados, já visando transformá-lo num grande evento esportivo para pessoas com deficiência. $^{25}$

Conexões: revista da Faculdade de Educação Física da UNICAMP, Campinas, v. 13, n. 4, p. 100-118, out./dez. 2015. ISSN: 1983-9030. 
Segundo Araújo ${ }^{6}$, concomitantemente nos Estados Unidos, Lipton e Nugent, passaram a treinar equipes de basquetebol utilizando cadeira de rodas. Em 1950, houve a união de Dr. Guttmann e Lipton, culminando no desenvolvimento dos Jogos de Mandeville que, contando com cada vez quantidade maior de atletas, modalidades e países, evoluíram e foram aceitos internacionalmente recebendo, em 1964, o nome de Paraolimpíadas, o qual se transformou em Paralimpíadas oficialmente em 2011, no Brasil.

Ainda de acordo com esse mesmo autor, no Brasil, o esporte adaptado começou por uma iniciativa popular. Robson Sampaio de Almeida e Sérgio Serafim Del Grande, ambos com condição de deficiência física, foram para os Estados Unidos realizar um programa de reabilitação, no qual tiveram contato com o esporte adaptado, e voltaram ao Brasil fundando o Clube dos Paraplégicos, em São Paulo, e o Clube dos Otimistas, no Rio de Janeiro, nos anos de 1950. Após essa iniciativa popular o governo brasileiro iniciou medidas relacionadas ao tema, num processo de institucionalização do esporte adaptado no Brasil, contando com várias ações politicas que visavam defender e garantir os direitos das pessoas com deficiência, além de popularizar essa prática no cenário nacional. Com isso, foi possível iniciar a prática de esporte pelas pessoas com deficiência também no setor educacional, trazendo mais uma forma de inclusão e de possibilidade para educação física escolar.

Inicialmente baseada apenas na ginástica, a educação física abdicou de maior espaço para o esporte enquanto conteúdo escolar apenas na década de 60, aproximadamente, quando a área passou por uma forte influência do tecnicismo sendo completamente esportivizada. O esporte tornou-se não apenas o conteúdo principal da educação física escolar, mas muitas vezes o único conteúdo, sendo utilizado de forma promover o preparo físico e a formação de atletas.

Assim como a educação física, o esporte educacional foi inicialmente explorado de acordo com interesses políticos e sociais, sendo fator de exclusão ao pregar os ideais de concorrência e rendimento e seleção dos mais habilidosos dentro do ambiente escolar, dificultando a participação de pessoas com deficiência, uma vez que elas não iriam atingir o desempenho esperado, mesmo com a já ocorrência da prática de esporte adaptado na sociedade, uma vez que esta ainda era discreta e desconhecida pela maioria populacional. Conexões: revista da Faculdade de Educação Física da UNICAMP, Campinas, v. 13, n. 4, p. 100-118, out./dez. 2015. ISSN: 1983-9030. 
Como citado anteriormente, na década de 70 a educação física passou por uma série de questionamentos e construção de novas teorias que passaram a nortear seu funcionamento. O esporte passou a ser visto como apenas um dentre os cinco principais conteúdos da educação física - que também englobam dança, ginástica, luta e jogo - e não como temática única. Porém, devido a essa circunstância histórica associada à valorização cultural destinado a esse conteúdo, as atividades esportivas mantiveram-se predominantes nas aulas de educação física escolar, em detrimento dos demais temas. Em nenhuma hipótese questiona-se sua presença, apenas é questionável sua superioridade que muitas vezes restringe a presença dos demais conteúdos.

Sabendo disso e da função segregadora atribuída de início ao esporte na educação física escolar, hoje se busca uma mudança nesse cenário, mudança essa associada ao novo contexto sócio-educacional no qual a educação física escolar tornou-se obrigatoriamente inclusiva. Neste sentido, relevante contribuição pode ser derivada da Lei Pelé, Lei $n^{\circ}$ 9.615/1998, a qual organizou princípios do cenário esportivo ao classificar o esporte como de rendimento - com a busca de desenvolvimento das capacidades físicas e técnicas visando a vitória sobre os adversários, de forma fundamentada no alto rendimento esportivo -, de participação - realizado nos momentos de lazer como forma de bem estar para os participantes - e educacional - sendo este o destinado a ser trabalhado nas escolas, com o objetivo de formação integral, cidadania e lazer. ${ }^{25}$

A forma adequada de exploração desse conteúdo, por conseguinte, foi não apenas esclarecida, mas também se respaldou em determinações legais. O esporte educacional, destinado ao âmbito escolar, é uma forma de oportunizar aos alunos a vivência de diferentes modalidades, respeitando a individualidade e objetivando a socialização, o desenvolvimento global do aluno e o ensino dos valores humanos. ${ }^{26,28}$

O esporte deve ser trabalho de forma a permitir a vivência de todos os alunos das diversas modalidades e possibilidades, permitindo que todos não apenas vivenciem, mas também transforme e recriem atividades de acordo com seus interesses e forma de compreensão.

Além disso, o esporte adaptado tem sido uma possibilidade a ser trabalhada pela educação física escolar. Além de serem mais uma forma de possibilitar a inclusão nas aulas de educação física, também podem auxiliar os alunos a terem maior conhecimento a respeito Conexões: revista da Faculdade de Educação Física da UNICAMP, Campinas, v. 13, n. 4, p. 100-118, out./dez. 2015. ISSN: $1983-9030$. 
das pessoas com deficiência e a desenvolverem outras percepções que não as comumente exploradas.

Atuando com o esporte de uma forma pedagógica e educacional, o professor pode auxiliar seus alunos no desenvolvimento das habilidades motoras e capacidades físicas, desenvolver capacidades cognitivas e a técnica e tática de diversas modalidades, despertar o interesse pela prática de esporte e atividades físicas ao longo da vida, discutir e transformar valores, estimular o desenvolvimento da autoconfiança, da autoestima e da capacidade de tomar decisão, desenvolver valores como cooperação e respeito. ${ }^{29,33}$

O esporte por si próprio não é nem pode ser definido como excludente ou inclusivo, mas depende da forma como é trabalhado e dos objetivos a ele associados. Sabendo da imensa importância sociocultural que ele representa, o professor de educação física não pode negligenciá-lo em suas aulas, mas também não deve repetir o trabalho esportivizado baseado na realização apenas de gestos técnicos e técnicos e na seleção dos mais habilidosos.

Houve uma mudança no cenário escolar tanto em aspectos legais, com a determinação da inclusão, quanto no plano educacional, com a busca pela construção das definições inclusivas e a superação das dificuldades encontradas para essa consolidação. E o esporte pode contribuir para o desenvolvimento desse processo inclusivo, por meio da vivência dos esportes adaptados específicos para a deficiência e também pela adaptação dos esportes convencionais segundo as necessidades do momento e do grupo de alunos, de forma a permitir uma participação ativa de todos. As possibilidades são muitas, dependendo apenas da criatividade e consciência do professor para atuar de forma adequada com esse conteúdo.

O professor de educação física possui um grande trunfo nas mãos, que é o domínio de um conteúdo supervalorizado e vivenciado socialmente. Se anteriormente foi utilizado como forma de segregação dos menos habilidosos, hoje pode ser uma forma muito eficaz de trabalhar os valores e a aceitação das diferenças, uma vez que um conteúdo com tão grande prestígio torna mais fácil as assimilações dos valores a ele associados do que em outros conteúdos com menor visibilidade.

Conexões: revista da Faculdade de Educação Física da UNICAMP, Campinas, v. 13, n. 4, p. 100-118, out./dez. 2015. ISSN: 1983-9030. 


\section{CONSIDERAÇÕES FINAIS}

A pessoa com deficiência alcançou direito legal sobre a educação física escolar. Contudo, barreiras sociais e culturais, numa sociedade que exalta a aptidão física e a competição, ainda dificultam sua participação efetiva. O esporte enquanto conteúdo educacional tem potencial relevante para a alteração desse cenário. Apesar de ser entendido socialmente como busca pela perfeição técnica e pela vitória competitiva, no âmbito educacional pode atuar de forma a exaltar a cooperação e a valorização das potencialidades de cada aluno. Um conteúdo de tanto prestígio tem influência relevante para transformar ideais.

Torna-se necessário, nesse momento, mais pesquisas sobre possibilidades práticas de trabalho, além da difusão das já feitas no ambiente acadêmico para o escolar, permitindo uma forma de trabalho diferenciada e adequada com esse conteúdo por parte dos professores. Se o esporte é o que os professores fazem dele, tornando-se competitivo ou inclusivo segundo sua orientação e prática pedagógica, esse conteúdo pode também atuar de forma a ser contribuidor ao desenvolvimento da inclusão na educação física escolar.

\section{REFERÊNCIAS}

${ }^{1}$ CHICON, J. F. Inclusão e exclusão no contexto da educação física escolar. Movimento, Porto Alegre, v. 14, n. 1, p. 13-38, jan./abr. 2008.

${ }^{2}$ KOCHE, J. C. Fundamentos de metodologia científica: teoria da ciência e iniciação a pesquisa. 23. ed. Petropolis: Vozes, 2006.

3PESSOTI, I. Deficiência mental: da superstição à ciência. São Paulo: T. A. Queiroz, 1984.

${ }^{4}$ MIRANDA, A. A. B. História, deficiência e educação especial. São Paulo: Universidade Federal de Uberlândia, 2003.

${ }^{5}$ STAINBACK, S.; STAINBACK, W. Inclusão: um guia para educadores. Porto Alegre: Artmed, 1999.

Conexões: revista da Faculdade de Educação Física da UNICAMP, Campinas, v. 13, n. 4, p. 100-118, out./dez. 2015. ISSN: 1983-9030. 
${ }^{6}$ ARAÚJO, P. F. A educação física para pessoas portadoras de deficiências nas instituições especializadas de Campinas. Campinas: Ed. da UNICAMP, 1999.

${ }^{7}$ MENDES, E. G. A. A radicalização do debate sobre inclusão escolar no Brasil. Revista Brasileira de Educação, Rio de Janeiro, v. 11, n. 33, p. 387-405, set./dez. 2006.

${ }^{8}$ SOLER, R. Educação física inclusiva: em busca de uma escola plural. Rio de Janeiro: Sprint, 2005.

${ }^{9}$ BRASIL. Ministério da Educação e Cultura. Declaração de Salamanca: sobre princípios, políticas e práticas na área das necessidades educativas especiais.

Disponível em: < portal.mec.gov.br/seesp/arquivos/pdf/salamanca.pdf > . Acesso em: 25 jun. 2014.

${ }^{10}$ FREIRE, P. Pedagogia da autonomia: saberes necessários a prática educativa. São Paulo: Paz e Terra, 1996.

${ }^{11}$ RAMOS, J. Os exercícios físicos na história e na arte. São Paulo: Ibrasa, 1982.

${ }^{12}$ DARIDO, S. C. Educação física na escola: questões e reflexões. Rio de Janeiro: Guanabara Koogan, 2003.

${ }^{13}$ CASTELLANI FILHO, L. Educação física no Brasil: a história que não se conta. 2. ed. Campinas: Papirus, 1991.

${ }^{14}$ KRUG, H. N. A inclusão de pessoas portadoras de necessidades educativas especiais na Educação Física escolar. Cadernos de Educação Especial, Santa Maria, n. 19, jan./abr. 2002.

${ }^{15}$ SILVA, R. F.; SEABRA JUNIOR, L.; ARAÚJO, P. F. Educação física adaptada no Brasil: da historia à inclusão educacional. São Paulo: Phorte, 2008.

Conexões: revista da Faculdade de Educação Física da UNICAMP, Campinas, v. 13, n. 4, p. 100-118, out./dez. 2015. ISSN: $1983-9030$. 
${ }^{16}$ ARAÚJO, P. F. Desporto adaptado no Brasil. São Paulo: Phorte, 2011.

${ }^{17}$ BRASIL. Senado Federal. Constituição da República Federativa do Brasil de 1988. Brasília, 1988.

${ }^{18}$ BRASIL. Ministério da Educação e Cultura. Plano Nacional de Educação. Lei no 10.172 , de 9 de janeiro de 2001. Aprova o Plano Nacional de Educação e dá outras providencias. Diário Oficial [da] República Federativa do Brasil, Brasília, 2001. Disponível em: <http://www.portal.mec.gov.br>. Acesso em: 15 set. 2013.

${ }^{19}$ GORGATTI, M. G.; COSTA, R. F. da. Atividade física adaptada. Barueri: Manole, 2005.

${ }^{20}$ SILVA, R. F. A ação do professor de ensino superior na educação física adaptada: construção mediada pelos aspectos dos contextos históricos, políticos e sociais. 2004. 184f. Dissertação (Mestrado em Atividade Motora Adaptada) - Faculdade de Educação Física, Universidade Estadual de Campinas, Campinas, 2004.

${ }^{21}$ VAGO, T. M. Pensar a educação física na escola: para uma formação cultural da infância e da juventude. Cadernos de Formação RBCE, v. 1, n. 1, p. 25/42, ago. 2009.

${ }^{22}$ PRONI, M. W.; LUCENA, R. Esporte, história e sociedade. Campinas: Autores Associados, 2002.

${ }^{23}$ BRACHT, V. Sociologia crítica do esporte: uma introdução. 3. ed. Ijuí: Ed. da Unijuí, 2006.

${ }^{24}$ WINNICK, J. P. Educação física e esportes adaptados. 3. ed. Barueri: Manole, 2004.

${ }^{25}$ BRASIL. Lei Pelé. Lei no 9.615, de 24 de março de 1998. Diário oficial [da] República Federativa do Brasil. Brasília, 1998. Disponível em:

<http://www.planalto.gov.br/ccivil/LEIS/L9615consol.htm>. Acesso em: 27 dez. 2012. Conexões: revista da Faculdade de Educação Física da UNICAMP, Campinas, v. 13, n. 4, p. 100-118, out./dez. 2015. ISSN: 1983-9030. 
${ }^{26}$ MELO FILHO, Á. Nova Lei Pelé: avanços e impactos. Rio de Janeiro: Maquinária, 2011.

${ }^{27}$ FERREIRA, V. Educação física, interdisciplinaridade, aprendizagem e inclusão. Rio de Janeiro: Sprint, 2006.

${ }^{28}$ MONTEIRO, A. A.; ALMEIDA, T. T. O. Educação física no ensino fundamental: com atividades de inclusão. 2. ed. São Paulo: Cortez, 2010.

${ }^{29}$ PAES, R. R.; BALBINO, H. F. Pedagogia do esporte: contextos e perspectivas. Rio de Janeiro: Guanabara Koogan, 2005.

${ }^{30}$ DIEHL, R. M. Jogando com as diferenças: jogos para crianças e jovens com deficiência em situação de inclusão e em grupos específicos. 2. ed. São Paulo: Phorte, 2008.

${ }^{31}$ FALKENBACH, A. P. Inclusão: perspectivas para as áreas da educação física, saúde e educação. Jundiaí: Fontoura, 2010.

${ }^{32}$ OLIVEIRA, V. M.; DECHICHI, C. Educação especial e educação física: saberes e praticas. Uberlândia: Com-poser, 2009.

${ }^{33}$ ALVES, M. L. T.; MOLLAR, T. H.; DUARTE, E. Educação física escolar: atividades inclusivas. São Paulo: Phorte, 2013.

Recebido em: 21 jul. 2014

Aceito em:22 out. 2015

Contato: camilalopes.c@hotmail.com

Conexões: revista da Faculdade de Educação Física da UNICAMP, Campinas, v. 13, n. 4, p. 100-118, out./dez. 2015. ISSN: 1983-9030 